\title{
The value of a core clinical rotation in urology for medical students
}

\author{
Premal Patel, MD; ${ }^{*}$ Jasmir G. Nayak, MD; ${ }^{\dagger}$ Thomas B. McGregor, MD, FRCSC \\ *University of Manitoba, Section of Urology, Winnipeg, MB; †University of Washington, Department of Urology, Seattle, WA
}

Cite as: Can Urol Assoc J 2015;9(11-12):392-6. http://dx.doi.org/10.5489/cuai.3297

Published online December 14, 2015.

\section{Abstract}

Introduction: In 2013, our institution underwent a change to the undergraduate medical curriculum whereby a clinical urology rotation became mandatory. In this paper, we evaluated the perceived utility and value of this change in the core curriculum.

Methods: Third year medical students, required to complete a mandatory 1-week clinical urology rotation, were asked to complete a survey before and after their rotation. Fourth year medical students, not required to complete this rotation, were also asked to complete a questionnaire. Chi-squared and Fisher's exact test were used for data analysis.

Results: In total, 108 third year students rotated through urology during the study period. Of these, 66 (61\%) completed the prerotation survey and 54 (50\%) completed the post-rotation survey. In total, there were 110 fourth year students. Of these, 44 (40\%) completed the questionnaire. After completing their mandatory rotations, students felt more comfortable managing and investigating common urological problems, such as hematuria and renal colic. Students felt they had a better understanding of how to insert a Foley catheter and felt comfortable independently inserting a Foley catheter. Importantly, students felt they knew when to consult urology and were also more likely to consider a career in urology. Compared to fourth year students, third year students felt urology was an important component to a family medicine practice and felt they had a better understanding of when to consult urology.

Conclusion: The introduction of a mandatory urology rotation for undergraduate medical students leads to a perceived improvement in fundamental urological knowledge and skill set of rotating students. This mandatory rotation provides a valuable experience that validates its inclusion.

\section{Introduction}

Urological medical conditions become more prevalent with age and represent common medical complaints in general medical practice. This is likely to become increasingly com- mon with a greater proportion of our population becoming elderly. In fact, the proportion of patients over the age of 65 in the United States was 15\% in 2015 and is expected to increase to $21 \%$ by $2030 .^{1}$ Similar trends are seen in Canada, with $22 \%$ to $24 \%$ of the population expected to be over 65 by $2030 .^{2}$ These population-based changes highlight the impending burden of urological conditions for the general practitioner, which are further compounded by a stagnant urology workforce. ${ }^{3}$ In fact, a recent study projects an increase in the number of men with lower urinary tract symptoms, for which the management may fall upon primary care physicians. ${ }^{3}$ Taken together, there is a critical need for both undergraduate and graduate medical education to manage future urological disease.

Medical school exposure to urology can be quite heterogeneous. ${ }^{4} \mathrm{~A}$ concerning finding in a recent Canadian study revealed that $44 \%$ of final year medical students considered their urological medical education insufficient, ${ }^{5}$ suggesting that contemporary medical graduates may lack the necessary knowledge and skill sets required to manage common urological problems. This is in keeping with the documented decline in urological education in the United States. ${ }^{6}$ One could imagine that lack of urological knowledge could lead to misdiagnosis and mismanagement, as well as poor resource utilization. Thus, identifying ways to improve these knowledge-discrepancies is important for the future curriculum of medical schools.

Historically, at our institution, didactic urological teaching took place through a series of lectures during the preclinical, second year of medical school. A recent change to our medical school curriculum was to add a mandatory 1 -week clinical rotation in urology to the surgical clerkship beginning in the 2013-2014 academic year. In this paper, we evaluated the effect of this mandatory rotation on the subjective, self-described knowledge and skill sets of rotating medical students. A survey-based approach was taken to assess the pre-rotation and post-rotation experiences of third year medical students who were the first cohort to participate in this new mandatory rotation. Further, we 
surveyed the fourth year medical students who completed clerkship without a mandatory urology rotation to serve as a comparative group. We hypothesized that the mandatory rotation would lead to a perceived improvement in urological knowledge, practical skills and an overall confidence in managing urologic conditions.

\section{Methods}

Mandatory rotations consisted of a 1-week rotation on the clinical urology service. Students were presented with a comprehensive booklet on common urological problems prior to the start of their rotation. Students typically experienced a combination of clinics, minor procedures and operating room exposures in addition to attending weekly urology resident teaching rounds. Three surveys were drafted (Table 1). The first online survey consisted of 14 questions and was sent electronically to third year medical students about 1 week before the start of their rotation (pre-rotation survey). After completing their rotations, students were asked to complete a follow-up survey via an online link to the survey. The opinions of fourth year students (no mandatory rotation) were obtained to serve as a control group. Survey participation was completely voluntary and no compensation was awarded. Statistical analysis was performed with Stata (Stata Corp., College Station, TX, version 14), with statistical significance at $p<0.05$.

\section{Results}

In total, 108 third year medical students rotated through urology during the study period. Of these, 66 (61\%) students responded to the pre-rotation survey and $54(50 \%)$ to the post-rotation survey. Of the 110 students in the fourth year class, $44(40 \%)$ responded to the questionnaire. Over 95\% of the third and fourth year students had no prior urological experience in their training.

From the results of the pre-rotation questionnaire, we found that most third year students felt they lacked basic urology knowledge, skills and comfort with handling common urologic conditions. When the answers to the same questions were asked on the post-rotation questionnaire, there was a statistically significant improvement regarding urological knowledge, basic urology skills and overall comfort in investigating and managing common urologic conditions. At the end of the mandatory rotation, $87 \%$ of students felt the rotation was beneficial and $89 \%$ of students were glad it was mandatory. Students were also more likely to consider a career in urology. There were no significant differences between the pre- and post-rotation questionnaire as to whether students felt that urology was a male dominated specialty, whether urology encompassed an important component to a family medicine practice, whether they would recommend a urology rotation to a colleague, and if the undergraduate medical exposure to urology was sufficient (Table 1).

When comparing third year students' post-rotation results to the responses by the fourth year students who had no mandatory urology rotation, we found major differences (Table 1). Overall, after completing the urology rotation, third year medical students had a better understanding of the role of a urologist, felt more comfortable inserting a Foley catheter, would more likely consider urology as a career, considered urology an important component to a family medicine practice, felt they knew when to consult urology, and were more likely recommend a urology rotation to a colleague. However, there were no statistically significant differences between the two groups with regards to feelings that urology was a male dominated specialty, understanding a Foley catheter insertion and attempt, and investigating and managing common urological conditions. Importantly, a significant proportion of fourth year medical students felt their exposure to urology during their medical education was inadequate.

\section{Discussion}

The role of undergraduate urological education in increasing theoretical knowledge, skill sets and shaping career decisions is seldom studied. Focusing on our institutional experience transitioning from an optional to mandatory urology rotation, we demonstrated that students who rotated through urology lead to a perceived improvement in knowledge, skill sets and confidence in managing common urological conditions. These findings highlight the vital role of early exposure to urology and validate this recent curriculum change.

Our findings make several important contributions to the literature. Our evaluation of fourth year medical students (no mandatory urology rotation) is in keeping with the University of British Columbia experience, ${ }^{5}$ in that a significant number of students (26\%) felt that their urological medical education was inadequate. In fact, others had cautioned that despite their single institution study, the results were likely representative of undergraduate urologic education across Canada. ${ }^{7}$ These findings are not unique to Canada. In 2013 Slaughenhoupt and colleagues surveyed 41 randomly selected accredited medical schools in the United States and found $49 \%$ of schools offered no preclinical urology lectures or small group sessions and only 2 (5\%) schools had a mandatory urology clinical rotation. ${ }^{8}$ This is not new, as demonstrated by Loughlin and colleagues. They found the proportion of medical schools in the United States offering urology as a mandatory rotation has decreased from $38 \%$ in 1994 to only $17 \%$ in $2004 .{ }^{6}$ This declining trend has also been shown by other investigators. ${ }^{9}$ These trends are concerning and support research efforts at quantifying the 
Patel et al.

Table 1. Survey results and corresponding data analysis, statistically significant findings in bold

\begin{tabular}{|c|c|c|c|c|c|c|}
\hline Questions & Answers & $\begin{array}{l}\text { Pre-rotation } \\
\text { survey }\end{array}$ & $\begin{array}{l}\text { Post-rotation } \\
\text { survey }\end{array}$ & $\begin{array}{l}p \text { value (Pre-rotation } \\
\text { vs. Post-rotation) }\end{array}$ & $4^{\text {th }}$ year & $\begin{array}{l}p \text { value (Post-rotation } \\
\text { vs. } 4^{\text {th }} \text { year students) }\end{array}$ \\
\hline \multirow{3}{*}{$\begin{array}{l}\text { 1. Have you performed a prior } \\
\text { formal urology elective? }\end{array}$} & 1 to 2 weeks & 1 & 3 & & 1 & \\
\hline & 2 to 4 weeks & 0 & 0 & & 1 & \\
\hline & None & 65 & 51 & & 42 & \\
\hline \multirow{3}{*}{$\begin{array}{l}\text { 2. I understand what a } \\
\text { urologist does and the } \\
\text { pathology they treat? }\end{array}$} & Disagree & 4 & 0 & & 3 & \\
\hline & Neutral & 19 & 1 & $<0.0001$ & 5 & 0.017 \\
\hline & Agree & 43 & 53 & & 36 & \\
\hline \multirow{3}{*}{$\begin{array}{l}\text { 3. Urology is a male dominated } \\
\text { specialty. }\end{array}$} & Disagree & 5 & 12 & & 6 & \\
\hline & Neutral & 16 & 13 & 0.071 & 11 & 0.64 \\
\hline & Agree & 44 & 29 & & 25 & \\
\hline \multirow{3}{*}{$\begin{array}{l}\text { 4. Urology is an important } \\
\text { component of a family } \\
\text { medicine practice. }\end{array}$} & Disagree & 2 & 0 & & 2 & \\
\hline & Neutral & 7 & 1 & 0.059 & 35 & $<0.0001$ \\
\hline & Agree & 57 & 53 & & 7 & \\
\hline \multirow{2}{*}{$\begin{array}{l}\text { 5. I understand how to insert a } \\
\text { Foley catheter. }\end{array}$} & Yes & 50 & 51 & \multirow{2}{*}{0.006} & 40 & \multirow{2}{*}{1.00} \\
\hline & No & 16 & 3 & & 3 & \\
\hline $\begin{array}{l}\text { 6. I have attempted a Foley } \\
\text { insertion previously (Pre- }\end{array}$ & Yes & 37 & 44 & & 35 & \\
\hline $\begin{array}{l}\text { rotation and } 4^{\text {tn }} \text { year students). } \\
\text { I have attempted a Foley } \\
\text { insertion during this rotation } \\
\text { (Post-rotation). }\end{array}$ & No & 29 & 9 & 0.003 & 8 & 1.00 \\
\hline \multirow{3}{*}{$\begin{array}{l}\text { 7. I feel comfortable inserting a } \\
\text { Foley catheter. }\end{array}$} & Disagree & 36 & 6 & & 19 & \\
\hline & Neutral & 15 & 15 & $<0.0001$ & 7 & 0.0014 \\
\hline & Agree & 15 & 33 & & 18 & \\
\hline \multirow{3}{*}{$\begin{array}{l}\text { 8. I feel comfortable } \\
\text { performing a digital rectal } \\
\text { examination to screen for } \\
\text { prostate cancer. }\end{array}$} & Disagree & 23 & 8 & & 7 & \\
\hline & Neutral & 9 & 6 & 0.026 & 12 & 0.087 \\
\hline & Agree & 34 & 40 & & 24 & \\
\hline \multirow{3}{*}{$\begin{array}{l}\text { 9. I feel comfortable } \\
\text { investigating/ managing } \\
\text { hematuria. }\end{array}$} & Disagree & 21 & 4 & & 6 & \\
\hline & Neutral & 28 & 8 & $<0.0001$ & 9 & 0.43 \\
\hline & Agree & 17 & 42 & & 29 & \\
\hline \multirow{3}{*}{$\begin{array}{l}\text { 10. I feel comfortable } \\
\text { investigating/ managing renal } \\
\text { colic. }\end{array}$} & Disagree & 21 & 3 & & 5 & \\
\hline & Neutral & 27 & 15 & $<0.0001$ & 10 & 0.58 \\
\hline & Agree & 17 & 36 & & 29 & \\
\hline \multirow{3}{*}{$\begin{array}{l}\text { 11. I know when and when not } \\
\text { to consult urology. }\end{array}$} & Disagree & 35 & 1 & & 13 & \\
\hline & Neutral & 19 & 11 & $<0.0001$ & 19 & $<0.0001$ \\
\hline & Agree & 11 & 42 & & 12 & \\
\hline \multirow{3}{*}{$\begin{array}{l}\text { 12. I think a urology rotation is } \\
\text { useful and would recommend } \\
\text { it to a friend. }\end{array}$} & Disagree & 0 & 1 & & 2 & \\
\hline & Neutral & 12 & 4 & 0.061 & 7 & 0.023 \\
\hline & Agree & 47 & 49 & & 19 & \\
\hline \multirow{3}{*}{$\begin{array}{l}\text { 13. I would consider urology as } \\
\text { a career. }\end{array}$} & Disagree & 26 & 16 & & 37 & \\
\hline & Neutral & 25 & 16 & 0.015 & 5 & $<0.0001$ \\
\hline & Agree & 15 & 21 & & 1 & \\
\hline \multirow{3}{*}{$\begin{array}{l}\text { 14. I think the undergraduate } \\
\text { medical exposure is: }\end{array}$} & Inadequate & 5 & 5 & & 11 & \\
\hline & Minimal & 35 & 24 & 0.22 & 28 & $<0.0001$ \\
\hline & Sufficient & 18 & 25 & & 4 & \\
\hline \multirow{3}{*}{$\begin{array}{l}\text { 15. I found this rotation very } \\
\text { beneficial. }\end{array}$} & Disagree & & 0 & & & \\
\hline & Neutral & & 7 & & & \\
\hline & Agree & & 47 & & & \\
\hline \multirow{3}{*}{$\begin{array}{l}\text { 16. I am glad this rotation is } \\
\text { mandatory. }\end{array}$} & Disagree & & 1 & & & \\
\hline & Neutral & & 5 & & & \\
\hline & Agree & & 48 & & & \\
\hline
\end{tabular}


benefit of undergraduate urological exposure if we are to invoke large-scale change.

With regards to how a urology rotation affects future career decisions, we found students who completed a mandatory rotation were more likely to consider urology as a potential career. This was also shown when we looked at third year students after they had completed their rotation compared with career choices of fourth year students who were not required to complete a rotation. However, a compounding factor would be that fourth year students have completed their mandatory rotations and have generally decided on their specialty of choice. Nonetheless, Kerfoot and colleagues ${ }^{10}$ also found that clinical exposure to urology, mentorship opportunities and the development of realistic perceptions regarding the specialty substantially influenced recruitment efforts into urology.

As one may expect, implementing a mandatory 1-week clinical urology rotation increased student comfort in managing common urological conditions, including inserting a Foley catheter. This is important as the burden of urologic disease in North America is quite immense and continues to rise with our aging population. ${ }^{11}$ This was also reflected in a study evaluating the changing healthcare needs with the projected increase in older Canadian men between 2005 and $2018 .^{3}$ Specifically, there is an anticipated substantial increase in males with lower urinary tract symptoms for which the management will likely fall on primary care physicians. ${ }^{3}$

We also found that rotating students showed improved comfort in determining when to consult urology, which has an impact on the management of urological complaints, as demonstrated by Mishail and colleagues. ${ }^{12}$ In their study, questionnaires were sent to attending staff, fellows, and residents within the department of internal medicine, preventative medicine, family medicine and geriatric medicine as well as medical students with questions pertaining to the management of common urological complaints. They found a significant insufficiency with regards to general urology knowledge for all groups, and that results were superior if a person had performed a prior rotation in urology. Our results also highlight this finding with fourth year students, having not completed a urology clinical rotation, who were less likely to understand the scope of a urology practice, thus risking the inappropriate use urological consult services.

Our findings must be considered in the context of our limitations. First, this was a single centre experience and our results may not apply to other jurisdictions. Secondly, our sample size was relatively small and consists of the first cohort of students to participate in the mandatory rotation. Third, our questionnaire was not validated; it was derived by consensus among co-authors. In this regard, given the unique nature of our research question, it was difficult to use validated tools; however, we used Likert scales to facilitate comparison between groups. Fourth, our post-rotation surveys were generally conducted within the first few weeks after completing the urology rotation. Whether the aforementioned benefits of the mandatory rotation persist was unclear. However, others have suggested that long-lasting benefits exist. ${ }^{11}$ Fifth, both surveys were sent to all medical students; therefore, there was a potential for different third year medical students responding to the pre-rotation and post-rotation questionnaire. This was highly unlikely, however, as students who completed the initial survey were likely to respond to the post-rotation survey.

\section{Conclusion}

The increasing burden of urological disease in the general population mandates increased exposure to the urological sciences. The introduction of a mandatory 1-week urology clinical rotation subjectively improved the perceived theoretical and practical urology knowledge required to manage common urological complaints. Our findings support the inclusion of a formal urology rotation in the undergraduate medical school curriculum.

Competing interests: The authors declare no competing financial or personal interests.

This paper has been peer-reviewed.

\section{References}

1. U.S. Census Bureau. Projections of the population by sex and age for the United States: 2015 to 2060. http://www.census.gov/population/projections/data/national/2014.html. Accessed October 26, 2015.

2. Statistics Canada. Distribution of the total population by age group, observed (1921-2013) and projected (2014 to 2063) according to low-growth scenario, medium-growth and high-growth scenarios, Canada. 2014. http://www.statcan.gc.ca/pub/91-520-x/2014001/c-g/desc/desc2.5-eng.htm. Accessed October 26, 2015.

3. Rawson NS, Saad F. The aging male population and medical care for benign prostatic hyperplasia in Canada. Can Urol Assoc J 2010;4:123-7. http://dx.doi.org/10.5489/cuaj.09092

4. Teichman JM, Monga $M$, Littlefield JH. Third year medical student attitudes toward learning urology. J Urol 2001;165:538-41. http://dx.doi.org/10.1097/00005392-200102000-00055

5. Hoag NA, Hamidizadeh R, MacNeily AE. Undergraduate exposure to urology: impact of the distributed model of medical education in British Columbia. Can Urol Assoc J 2013;7:20-5. htrp://dx.doi.org/10.5489/ cuaj.277

6. Loughlin KR. The current status of medical student urological education in the United States. I Urol 2008;179:1087-90. http://dx.doi.org/10.1016/i.juro.2007.10.068

7. Rourke K. Teaching undergraduate urology: It takes a village. Can Urol Assoc J 2013;7:26-7. http:// dx.doi.org/10.5489/cuaj.227

8. Slaughenhoupt $B$, Ogunyemi 0 , Giannopoulos $M$, et al. An update on the current status of medical student urology education in the United States. Urology 2014;84:743-7. http://dx.doi.org/10.1016/i. urology.2014.06.003

9. Kerfoot BP, Masser BA, Dewolf WC. The continued decline of formal urological education of medical students in the United States: Does it matter? J Urol 2006;175:2243-7. http://dx.doi.org/10.1016/ S0022-5347(06)00314-4

10. Kerfoot BP, Nabha KS, Masser BA, et al. What makes a medical student avoid or enter a career in urology? Results of an international survey. J Urol 2005;174:1953-7. http://dx.doi.org/10.1097/01. ju.0000177462.61257.4e 
Patel et al.

11. Miller DC, Saigal CS, Litwin MS. The demographic burden of urologic disease in America. Urol Clin North Am 2009;36:11-27. http://dx.doi.org/10.1016/i.ucl.2008.08.004

12. Mishail A, Shahsavari $M$, Kim J, et al. Deficits in urological knowledge among medical students and primary care providers: Potential for impact on urological care. J Urol 2008;180:2140-7. http://dx.doi. org/10.1016/i.juro.2008.07.043

Correspondence: Dr. Premal Patel, Section of Urology, University of Manitoba, 820 Sherbrook Street, Winnipeg, MB R3A 1R9; premalpatel8@gmail.com

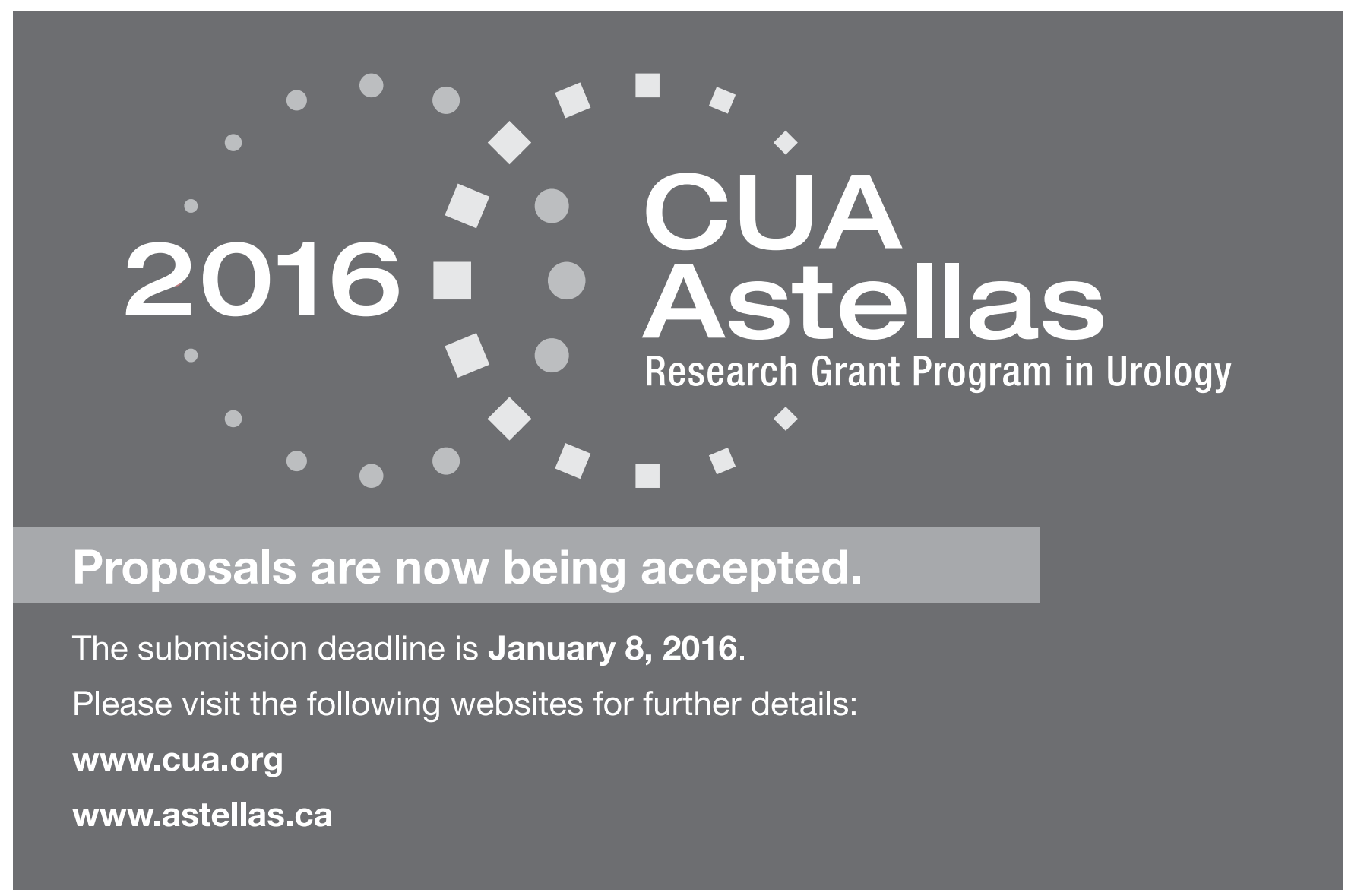

